\title{
Identifying risk factors for L'Hermitte's sign after IMRT for head and neck cancer
}

Hannah M. Laidley ${ }^{1,2^{*}}$ (D) David J. Noble ${ }^{2,3}$, Gill C. Barnett ${ }^{2,3}$, Julia R. Forman²,4, Amy M. Bates², Richard J. Benson², Sarah J. Jefferies², Rajesh Jena ${ }^{2}$ and Neil G. Burnet ${ }^{2,5}$

\begin{abstract}
Background: L'Hermitte's sign (LS) after chemoradiotherapy for head and neck cancer appears related to higher spinal cord doses. IMRT plans limit spinal cord dose, but the incidence of LS remains high.

Methods: One hundred seventeen patients treated with TomoTherapy ${ }^{\mathrm{TM}}$ between 2008 and 2015 prospectively completed a side-effect questionnaire (VoxTox Trial Registration: UK CRN ID 13716). Baseline patient and treatment data were collected. Radiotherapy plans were analysed; mean and maximum spinal cord dose and volumes receiving 10, 20, 30 and 40 Gy were recorded. Dose variation across the cord was examined. These data were included in a logistic regression model.

Results: Forty two patients (35.9\%) reported LS symptoms. Concurrent weekly cisplatin did not increase LS risk ( $p=$ $0.70, \mathrm{OR}=1.23\{95 \% \mathrm{Cl} 0.51-2.34\}$ ). Of 13 diabetic participants (9 taking metformin), only 1 developed LS ( $p=0.025$, $\mathrm{OR}=0.13\{95 \% \mathrm{Cl} 0.051-3.27\}$ ). A refined binary logistic regression model showed that patients receiving unilateral radiation $(p=0.019, \mathrm{OR}=2.06\{95 \% \mathrm{Cl} 0.15-0.84\})$ were more likely to develop $\mathrm{LS}$. Higher $\mathrm{V}_{40 \mathrm{~Gy}}(p=0.047, \mathrm{OR}=1.06$ $\{95 \% \mathrm{Cl} 1.00-1.12\}$ ), and younger age (mean age 56.6 vs 59.7, $p=0.060, \mathrm{OR}=0.96\{95 \% \mathrm{Cl} 0.92-1.00\}$ ) were associated with elevated risk of $L S$, with borderline significance.
\end{abstract}

Conclusions: In this cohort, concomitant cisplatin did not increase risk, and LS incidence was lower in diabetic patients. Patient age and dose gradients across the spinal cord may be important factors.

Keywords: Chemoradiotherapy, Cisplatin, Head and neck neoplasms, Spinal cord, Transverse myelitis

\section{Background}

With contemporary techniques, transverse myelitis following radical radiotherapy (RT) for head and neck cancer (HNC) is extremely rare. The QUANTEC paper of 2010 quotes a risk of $<1 \%$ at 54 Gy with conventional fractionation [1], and recent randomised trials have mandated maximum spinal cord (SC) doses much lower than this $[2,3]$. However, milder spinal cord toxicity in the form of L'Hermitte's sign (LS) may be more prevalent.

LS is characterised by electric-shock sensations down the spine and into limbs on neck movement (particularly flexion). It is a well-recognised symptom of demyelinating

\footnotetext{
* Correspondence: hlaidley@doctors.org.uk

${ }^{1}$ Foundation Doctor, Northampton General Hospital, Cliftonville, Northampton NN1 5BD, UK

${ }^{2}$ VoxTox Research Group, Cambridge University Dept. of Oncology, Hutchison/MRC Research Centre, Box 197 Cambridge Biomedical Campus, Cambridge CB2 OXZ, UK

Full list of author information is available at the end of the article
}

conditions such as Multiple Sclerosis (MS) [4], and can also occur as a side effect of radiation to the cervical or thoracic spinal cord [5]. The mechanism is believed to be transient inhibition of oligodendrocyte proliferation leading to reversible demyelination [6, 7]. LS usually develops in the first few months after radiotherapy, and seldom lasts more than 6 months [7-9], but can be unpleasant and distressing for patients. No clear link between radiogenic LS and progressive irreversible myelitis has been established, although delayed radiation-induced myelopathy causing paralysis may be preceded by LS [9].

Historical series, in which patients were treated with conformal, field-based techniques, report a risk of LS following RT for HNC between 3 and 13\% [9-11]. More recent work on LS following Intensity Modulated RT (IMRT) for thoracic and head and neck malignancy describes an incidence between 15 and 29\% [5, 12, 13]. Since IMRT permits superior sparing of critical organs 
at risk (OARs), and given our previous understanding of the dose-response relationship of the spinal cord [1, 14], these results are surprising. Recent research has indicated that younger age and higher maximum dose are risk factors, and inferred that concomitant chemotherapy may also be implicated $[13,15]$.

IMRT can generate steep dose gradients in order to adequately treat target volumes, whilst sparing OARs such as the SC. This often results in inhomogeneous dose distributions across OARs, and work on rat models has suggested that such inhomogeneity may be a risk factor for LS [16]. Whilst some clinical data appears to support this notion [12], no convincing evidence of a 'bath and shower' effect has yet been seen [13].

We sought to examine the link between radiation dose, comorbidities, and concomitant systemic therapy and the subsequent development of LS using a logistic regression model, in a cohort of patients with HNC recruited to the VoxTox study.

\section{Methods}

\section{Study design \& patient selection}

VoxTox is a longitudinal observational study to collect toxicity data for patients undergoing image-guided IMRT [17]. It received National Research Ethics Service (NRES) Committee East approval in February 2013 (13/ $\mathrm{EE} / 0008)$ and is part of the UK Clinical research network Study Portfolio (UK CRN ID 13716).

Adults undergoing curative RT with daily image guidance (IG) for histologically confirmed HNC are eligible for the broader study. This work included patients with squamous cell carcinomas (SCC's) and salivary gland tumours (SGT's) undergoing treatment to the primary site and neck with a minimum of 30 fractions. Prescription doses of 60Gy and above were permitted, and for patients to be included, a minimum of ipsilateral nodal levels II and III needed to be included in the neck CTV. As new LS beyond the first year is rare [9], a minimum follow up of 1 year was mandated. The following factors were regarded as exclusion criteria; incomplete baseline screening of past medical history, shorter fractionation schedules (fraction size $>2.17 \mathrm{~Gy}$ ), primary site radiation only, documented neurological comorbidity, nonspecific neurological symptoms (e.g. numbness and tingling) at baseline, and insufficient follow up.

\section{Patient treatment}

All patients in this study underwent helical IMRT on the TomoTherapy HiArt ${ }^{\mathrm{Tw}}$ system with daily IG [18]. Immobilisation was with a thermoplastic shell, and simulation performed on a planning-CT with $3 \mathrm{~mm}$ slices. Diagnostic imaging including MRI and PET-CT was rigidly coregistered to aid contour definition. A 3-dose, 30 fraction technique was used for SCCs. Gross primary and nodal disease CTV's received 65Gy, high-risk elective regions 60Gy and lower risk neck CTVs 54Gy in line with recent trial protocols [2]. Post-operative patients (both SCC's and SGT's) underwent adjuvant RT following surgery and received 60Gy in 30 fractions to primary site and elective nodal regions depending on risk. A PTV margin of $5 \mathrm{~mm}$ was used for all target volumes. The SC (not canal) was contoured as an OAR, with a $3 \mathrm{~mm}$ PRV margin. A maximum dose objective of 46Gy and absolute dose constraint of 50 Gy to the SC PRV were defined.

Fit patients (KPS $\geq 80)$ up to 70 years old with Stage IIIIV SCC received concomitant weekly cisplatin $\left(40 \mathrm{mg} / \mathrm{m}^{2}\right)$, or cetuximab $\left(400 \mathrm{mg} / \mathrm{m}_{2}\right.$ loading dose, $250 \mathrm{mg} / \mathrm{m}^{2}$ weekly dose) if specific contraindications to cisplatin existed [19]. Chemotherapy records were retrospectively accessed to define how many cycles of systemic therapy patients received. Baseline characteristics are listed in Table 1.

\section{Toxicity assessment}

Using both the CTCAE v4.03, and LENT-SOM(A) scales, patients had toxicity assessments undertaken at baseline, and 3, 6 and 12 months post-treatment $[20,21]$. Interviews were undertaken by the study research radiographer. Patients were asked about symptoms of LS, and responses were logged digitally at interview into a database within MOSAIQ ${ }^{\circ}$ (Elekta, Stockholm, Sweden) care management software.

CTCAE v4.03 was used for the primary analysis. Symptoms consistent with LS qualified as Grade 1 myelitis. On this basis, patients were categorised as either having LS or not. Previous studies show that the average duration of LS is $4-6$ months $[10,11,13]$. We therefore took a single positive response as sufficient to define patients as having developed LS. The LENT-SOM(A) scale was used to grade severity of symptoms from 0 to 4 , and this data informed a secondary ordinal analysis. The relevant question from the clinical reporting form is found in supplementary materials (Additional file 1: Figure. S1).

\section{Spinal cord dosimetry}

Planning CT images, structure sets and dose cubes were reloaded into RT contouring software ProSoma v3.3 (MedCom GmbH, Darmstadt, Germany). To minimise bias from inter-observer contouring variability, the spinal cord was re-contoured for all cases by one observer (DJN). To replicate the methodology of a similar study [13], two separate volumes were created; 'whole cord' and 'short cord' (Fig. 1a). Whole cord was defined by foramen magnum superiorly, and inferior extent of the planning scan, usually carina, inferiorly. The short cord volume was created by deleting slices caudal to the most inferior PTV slice. ProSoma was used to compute cumulative DVH's for both structures. The whole cord volume was used to calculate the maximum point dose 
Table 1 Patient characteristics univariate analysis

\begin{tabular}{|c|c|c|c|c|}
\hline & Non-LS $(n=75)$ & $\operatorname{LS}(n=42)$ & Odds Ratio (95\% Cl) & $p$-value \\
\hline \multicolumn{5}{|l|}{ Patient characteristics } \\
\hline Mean age $\pm S D$ & $59.7 \pm 8.7$ & $56.6 \pm 11.4$ & $0.96(0.93-1.01)$ & $0.1^{\mathrm{a}}$ \\
\hline -Difference $(95 \%$ Cl) & $3.1(-0.9$ to 7$)$ & & & \\
\hline -Age range & $34-79$ & $38-78$ & & \\
\hline Male & $64(85 \%)$ & $33(79 \%)$ & $0.63(0.3-2.2)$ & $0.4^{\mathrm{b}}$ \\
\hline -Difference (95\% Cl) & $-6.7 \%(-21.5$ to 8.1$)$ & & & \\
\hline \multicolumn{5}{|l|}{ Tumour characteristics } \\
\hline SCC & 68 (90.7\%) & $36(85.7 \%)$ & $0.62(0.3-2.6)$ & $0.2^{\mathrm{b}}$ \\
\hline -Oropharynx & $43(57.3 \%)$ & $26(61.9 \%)$ & & $>0.9$ \\
\hline -Oral Cavity & $9(12.0 \%)$ & $2(4.8 \%)$ & & 0.4 \\
\hline -Larynx & $8(10.6 \%)$ & $2(4.8 \%)$ & & 0.4 \\
\hline- CUP & $6(8.0 \%)$ & $1(2.4 \%)$ & & 0.3 \\
\hline -Hypopharynx & $1(1.2 \%)$ & $2(4.4 \%)$ & & $>0.9$ \\
\hline -Nasopharynx & $1(1.2 \%)$ & $3(6.7 \%)$ & & $>0.9$ \\
\hline Salivary gland & 7 (9.3\%) & $6(14.3 \%)$ & $1.6(0.4-3.9)$ & $>0.9$ \\
\hline \multicolumn{5}{|l|}{ Treatment plan } \\
\hline$\geq 65$ Gy prescribed & $60(80.0 \%)$ & $31(73.8 \%)$ & $0.71(0.4-2.1)$ & $0.7^{\mathrm{b}}$ \\
\hline Unilateral radiotherapy & $20(26.7 \%)$ & $18(42.8 \%)$ & $2.06(0.6-3.0)$ & $0.07^{b}$ \\
\hline Cisplatin prescribed & 39 (52.0\%) & 26 (61.9\%) & $1.5(0.6-2.6)$ & $0.3^{b}$ \\
\hline -Cisplatin received & 39 (52.0\%) & $24(57.1 \%)$ & $1.23(0.5-2.3)$ & $0.7^{b}$ \\
\hline Cetuximab prescribed & $8(10.7 \%)$ & $2(4.8 \%)$ & $0.42(0.1-3.4)$ & $0.3^{b}$ \\
\hline No chemotherapy & $28(37.3 \%)$ & $14(33.3 \%)$ & $0.84(0.4-2.1)$ & $0.8^{\mathrm{b}}$ \\
\hline \multicolumn{5}{|l|}{ Neurological Risk Factors } \\
\hline Hypertension & $25(33.3 \%)$ & $8(19.0 \%)$ & $0.47(0.3-1.79)$ & $0.1^{\mathrm{b}}$ \\
\hline Diabetes & $12(16.0 \%)$ & $1(2.4 \%)$ & $0.13(0.1-3.3)$ & $0.03^{b}$ \\
\hline
\end{tabular}

Abbreviations: $\mathrm{Cl}$ - confidence interval, $S D$ - standard deviation, $C U P$ - cancer of unknown primary a Student's $\mathrm{t}$ test, ${ }^{\mathrm{b}}$ Fisher's exact test

to the spinal cord $\left(D_{\max }\right)$, and the minimum dose to the $2 \mathrm{~cm}^{3}$ of the spinal cord receiving the highest dose $\left(D_{2 \mathrm{cc}}\right)$ , as well as the absolute volumes receiving 10, 20, 30 and 40Gy respectively $\left(\mathrm{V}_{10 G y}, \mathrm{~V}_{20 G y}, \mathrm{~V}_{30 G y}, \mathrm{~V}_{40 G y}\right)$ [13]. The short cord volume was used to calculate mean and median dose to the cervical cord, and relative volumes receiving $10,20,30$ and 40 Gy respectively $\left(V_{10 \%}, V_{20 \%}\right.$, $\left.\mathrm{V}_{30 \%}, \mathrm{~V}_{40 \%}\right)$.

To investigate the effect of dose inhomogeneity $[12,13]$, DVH data for short cord volumes were used to calculate homogeneity index, defined as $\left(D_{2 \%}-D_{98 \%}\right) / D_{50 \%}[22]$. An example patient with LS, and a significant axial dose gradient across the spinal cord, is shown in Fig. 1b.

\section{Statistics}

A refined logistic regression model was developed in three steps: 1) Univariate analyses 2) Logistic regression model 3) Refined logistic regression model. Univariate relationships between LS incidence and baseline parameters, chemotherapy and radiotherapy data were analysed using Fisher's Exact test if they were binary, student's t- test if data were parametric (determined by ShapiroWilk test), and Mann-Whitney U test if not. Odds ratios with $95 \%$ confidence intervals were calculated for independent variables. Estimates of the confidence intervals between medians are shown in Table 2 [23]. A receiver operator characteristic (ROC) curve analysis was used to assess the relationship between number of cycles of cisplatin received, and the incidence of LS.

Variables were included in a regression model based on three criteria: (i) biological plausibility and evidence from previous studies, (ii) collinearity statistics to reduce confounding, (iii) univariate analysis association at the $p<0.15$ level. Automated subset selection algorithms were not used, nor was selection based solely on univariate statistics, as these methods may conflate chance effects and reduce the reliability of models in biological systems [24]. Instead variables that fit the three criteria above were used to produce a regression model. Finally, the model was refined by removing all variables where $p>0.15$ and recalculating the regression model. Statistical analysis was 


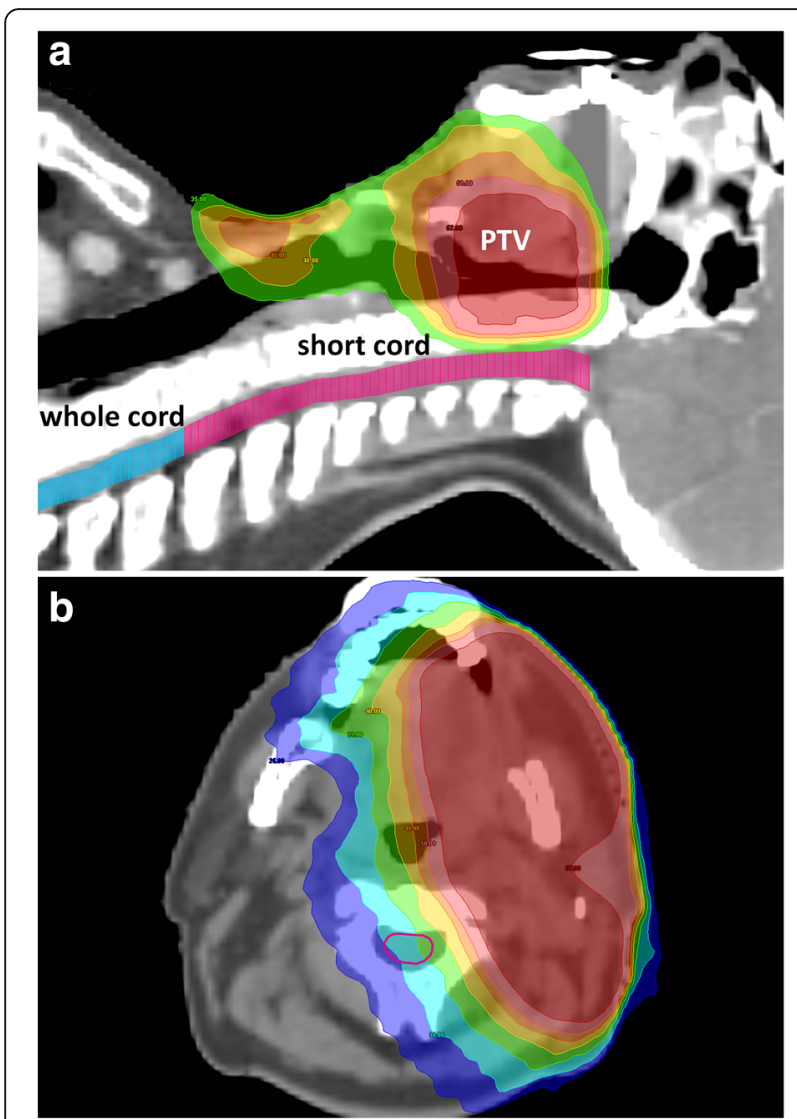

Fig. 1 Spinal cord dosimetry a 'whole cord' shown in blue, 'short cord' in pink. $\mathbf{b}$ axial dose gradient across the cervical cord; max. Left - right gradient 8.3Gy (36.9-28.6Gy). Dose wash; 95\% isodose for 60Gy (57.9Gy) dark red, 50Gy light red, 45Gy orange, 40Gy amber, 35Gy green, 30Gy light blue, 25Gy royal blue performed using IBM SPSS v23, and R statistical software ( $\mathrm{R}$ Notebook, $\mathrm{R}$ version v3.4.0, $\mathrm{R}$ Foundation for Statistical Computing).

\section{Results}

One hundred seventeen patients were included in the final analysis, and 42 patients (35.9\%) reported LS symptoms at least once: 29 reported Grade 1 LS, 11 Grade 2, two people had Grade 3 symptoms, and none reported Grade 4. Mean onset of LS symptoms was 5.4 months; median duration was 6 months.

\section{Univariate analyses}

Cisplatin prescription (as a binary variable) was not associated with LS development (Table 1). As cisplatin was administered weekly, ROC curve analysis was used to test the hypothesis that patients receiving a greater $\mathrm{cu}$ mulative dose might be at greater risk, despite the absence of a relationship as a binary variable (Fig. 2). This confirmed that the number of cycles of cisplatin received had no impact on incidence of LS (ROC curve AUC $=0$. 53, 95\% CI 0.43-0.63). However, younger patients were more likely to get cisplatin, (mean age $56.1+/-7.8$ vs $61.7+/-11.1, p=0.0017$ ), whilst diabetic and hypertensive patients were less likely to receive the drug $(p=0$. 0036 and $p=0.017$ respectively). Univariate analysis showed possible relationships between LS and all 3 factors (Table 1). Therefore, to mitigate the potential for these factors confounding and masking a real effect from concomitant chemotherapy, cisplatin was included in the first iteration of the logistic regression model.

Unilateral neck treatment tends towards significance on univariate analysis, despite mean $\mathrm{D}_{\max }$ being lower in patients treated unilaterally than those undergoing bilateral neck irradiation (35.4 vs 36.9Gy). This difference did not reach significance at the $5 \%$ level $(p=0.08$, Additional file 1 :

Table 2 Univariate analysis of SC Dose parameters and LS incidence

\begin{tabular}{|c|c|c|c|c|}
\hline & Non-LS $(n=75)$ & $\operatorname{LS}(n=42)$ & Difference $(95 \% \mathrm{Cl})$ & $p$ value (2-tailed) \\
\hline$D_{\max }$ & $36.4 \pm 4.7$ & $36.6 \pm 5.3$ & $0.27(-1.6-2.1)$ & $0.8^{\mathrm{a}}$ \\
\hline$D_{2 c c}$ & $33.1 \pm 4.8$ & $33.0 \pm 5.6$ & $0.10(-1.9-2.1)$ & $0.9^{\mathrm{a}}$ \\
\hline$D_{\text {mean }}$ & $29.4 \pm 5.4$ & $28.4 \pm 4.9$ & $1.0(-0.9-2.9)$ & $0.3^{\mathrm{a}}$ \\
\hline $\mathrm{HI}$ & $0.48 \pm 0.27$ & $0.57 \pm 0.22$ & $0.093(0.002-0.2)$ & $0.05^{\mathrm{a}}$ \\
\hline$V_{10 G y}$ & $14.3 \pm 3.3$ & $14.0 \pm 2.9$ & $0.35(-0.8-1.5)$ & $0.6^{\mathrm{a}}$ \\
\hline$V_{20 G y}$ & $12.4 \pm 3.7$ & $11.5 \pm 3.4$ & $0.90(-0.4-2.2)$ & $0.3^{\mathrm{a}}$ \\
\hline$V_{30 G y}$ & $7.6(1.9-11.3)$ & $4.9(1.6-8.5)$ & $2.7(-0.3-5.7)$ & $0.1^{\mathrm{b}}$ \\
\hline$V_{40 G y}$ & $0(0-0.03)$ & $0(0-0.15)$ & $0(0-0)$ & $0.9^{b}$ \\
\hline$V_{10 \%}$ & $100(100-100)$ & $100(100-100)$ & $0(0-0)$ & $0.7^{b}$ \\
\hline$V_{20 \%}$ & $99.5(91.2-100)$ & 96.4 (79.9-99.3) & $3.1(-1.1-7.4)$ & $0.02^{\mathrm{b}}$ \\
\hline$V_{30 \%}$ & $61.60(14.5-86.8)$ & $41.6(13.9-70.6)$ & $20(-2-41)$ & $0.1^{b}$ \\
\hline$V_{40 \%}$ & $0(0-0.19)$ & $0(0-1.16)$ & $0(0-0)$ & $0.9^{\mathrm{b}}$ \\
\hline
\end{tabular}

Abbreviations: $\mathrm{Cl}$ - confidence interval, $\mathrm{HI}$ - homogeneity index ${ }^{\mathrm{a}} \mathrm{Mean} \pm \mathrm{SD}$ and Student's $\mathrm{t}$ test, ${ }^{\mathrm{b}}$ Median, Interquartile range and Mann Whitney $\mathrm{U}$ test 

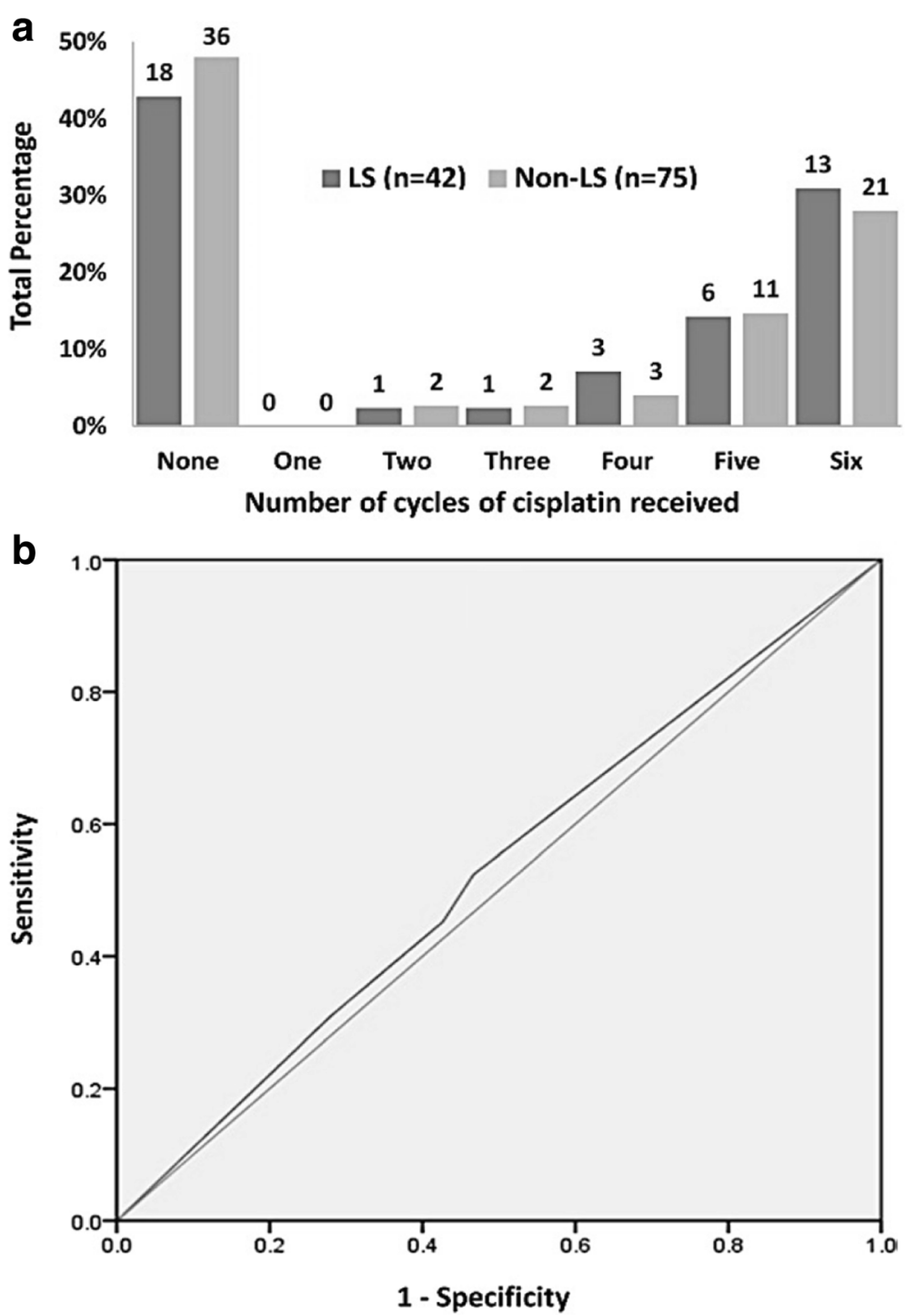

Fig. 2 Number of cycles of cisplatin received vs incidence of LS a number of cisplatin cycles received by patients with and without LS (absolute numbers above bars). $\mathbf{b}$ - Receiver Operator Characteristic curve - number of cisplatin cycles received for prediction of $L S(A \cup C=0.525,95 \% \mathrm{Cl}=$ 0.416 to 0.634$)$

Figure S2). Homogeneity index was slightly higher in patients with LS $(p=0.049)$ and significantly higher in patients receiving unilateral treatment $(p=0.0004)$ (Table 2, Fig. 3).

Both mean and maximum SC dose was similar in patients with and without LS (Table 2). Only $28.6 \%$ of patients who developed LS, but also $26.7 \%$ of patients who did not, had SC $D_{\max } \geq 40$ Gy $(p=0.8)$. Some dose parameters $\left(V_{30 \text { Gy }}, V_{40 G y}, V_{10 \%}, V_{20 \%}, V_{30 \%}, V_{40 \%}\right)$ were not normally distributed (because they were mostly 0 or 100 - Additional file 1: Figure S3) and could not be transformed to fit a normal distribution. Using the Mann Whitney $\mathrm{U}$ test three dose parameters were associated at the $p<0.15$ level; $\mathrm{V}_{20 \%}, \mathrm{~V}_{30 \%}$, and $\mathrm{V}_{30 \mathrm{~Gy}}$. The latter two were excluded to avoid multi-collinearity (Additional file 1: Figure S4 and Table S1).
Previous studies show that higher SC dose is more likely to cause LS or myelitis [7, 11, 15], with absolute or partial volumes over 40 Gy seemingly most predictive for LS [13]. SC doses in our series are substantially lower than these studies, and the absence of a relationship between $\mathrm{V}_{40 \mathrm{~Gy}} / \mathrm{V}_{40 \%}$ and LS on univariate analysis $(p=0.85$ and 0.86 respectively) may have been influenced by the low proportion of patients receiving $\geq 40$ Gy (27\%). Those that did had only small volumes of SC receiving 40 Gy (mean $1.44 \mathrm{~cm}^{3}$ ). $\mathrm{V}_{40 \mathrm{~Gy}}$ metrics were therefore included in the logistic regression model, to directly compare with previous work in the field, to account for possible bias on univariate analysis, and to strengthen our initial assertion if univariate analysis results were reproduced. 

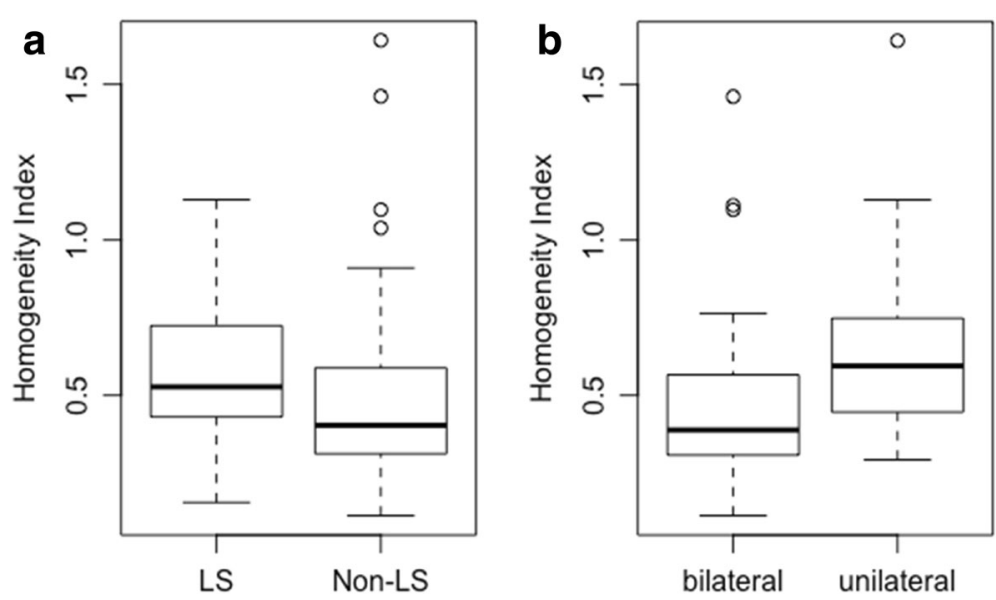

Fig. 3 Dose inhomogeneity in patients with and without LS a Box and whisker plots showing higher homogeneity index in LS patients $\mathbf{b}$ higher homogeneity index in patients receiving unilateral neck radiation.

\section{Logistic regressions}

A binary logistic regression model (LS vs Non-LS) was produced - Table 3. Age, unilateral vs bilateral radiation (laterality), homogeneity index, diabetes, and hypertension were included as they trended towards significance on univariate analysis $(p<0.15$, Tables 1 and 2). Cisplatin, $\mathrm{V}_{20 \%}$ and $\mathrm{V}_{40 \%}$ were included as described. The model was refined by removing variables with a $p$ value over 0.15 . This refined model found 3

Table 3 Binary logistic regression with LS vs Non-LS as the dependent variable

\begin{tabular}{|c|c|c|c|}
\hline $\begin{array}{l}\text { Independent } \\
\text { Variable }\end{array}$ & $\begin{array}{l}\text { Logistic regression } \\
\text { coefficient }\end{array}$ & $\begin{array}{l}\text { Regression } \\
p \text { value }\end{array}$ & $\begin{array}{l}\text { Odds Ratio }{ }^{a} \\
(95 \% \mathrm{Cl})\end{array}$ \\
\hline \multicolumn{4}{|l|}{ Original model } \\
\hline Age & -0.034 & 0.1 & $0.97(0.9-1.0)$ \\
\hline Laterality & -1.037 & 0.05 & $0.35(0.13-1.0)$ \\
\hline Diabetes & 2.166 & 0.06 & $8.7(0.9-83)$ \\
\hline Hypertension & 0.384 & 0.5 & $1.5(0.5-4.3)$ \\
\hline Cisplatin & -0.384 & 0.4 & $0.68(0.3-1.8)$ \\
\hline$V_{20 \%}$ & -0.007 & 0.7 & $0.99(0.96-1.0)$ \\
\hline$V_{40 \%}$ & 0.059 & 0.05 & $1.06(1.0-1.1)$ \\
\hline $\begin{array}{l}\text { Homogeneity } \\
\text { Index }\end{array}$ & 1.151 & 0.3 & $3.2(0.3-30)$ \\
\hline Constant & -0.129 & & \\
\hline \multicolumn{4}{|l|}{ Refined model } \\
\hline Age & -0.041 & 0.06 & $0.96(0.9-1.0)$ \\
\hline Laterality & -1.048 & 0.019 & $0.35(0.2-0.8)$ \\
\hline Diabetes & 2.301 & 0.036 & $10(1-85)$ \\
\hline$V_{40 \%}$ & 0.056 & 0.047 & $1.1(1.0-1.1)$ \\
\hline Constant & 0.200 & & \\
\hline
\end{tabular}

Abbreviations: $\mathrm{Cl}$ - confidence interval Hosmer and Lemeshow test refined model X2 (7) $=6.056, p=0.553$. Pseudo- $\mathrm{R}^{2}=0.14$ to 0.18 . ${ }^{\mathrm{a}}$ Odds ratio per unit increase in variable or for bilateral radiation and being non-diabetic predictors of LS with a pre-defined $\alpha<0.05$ : unilateral neck radiation, higher percentage volumes receiving 40 Gy or more, and absence of diabetes.

An ordinal regression (highest grade of LS reported as the dependent variable) was also undertaken to investigate an association with more severe symptoms (Additional file 1: Table S2). This suggested younger age is also a significant predictor of LS $(p=0.031)$.

It is possible that by using relative dose-volume parameters in the primary analysis, small differences in absolute volume were magnified $\left(\mathrm{V}_{40 \text { Gy }}\right.$ range; 0 to 8 . $2 \mathrm{cc}, \mathrm{V}_{40 \%}$ range; from 0 to $66.4 \%$ ). To account for this effect, the analysis was repeated using $V_{20 \text { Gy }}$ and $V_{40 G y}$ instead of $\mathrm{V}_{20 \%}$ and $\mathrm{V}_{40 \%}$ (Additional file 1: Tables $\mathrm{S} 3$ and S4). The outcome was very similar; in this model predictors of LS included younger age $(p=0.028)$, unilateral treatment $(p=0.042)$, higher absolute volumes receiving 40 Gy $(p=0.025)$, and absence of diabetes ( $p$ $=0.033) . V_{20 \text { Gy }}$ was predictive in the ordinal regression $(p=0.021)$.

\section{Discussion}

This is the largest prospective study of L'Hermitte's syndrome in HNC patients in the era of IG-IMRT. LS incidence in our cohort is higher than previously reported (3.6-29\%) [5, 11-13, 15], although mean onset and duration of symptoms were similar. The high incidence may be due to its prospective nature, and the fact that a single positive response classified patients as having LS. As LS is transient [9], we believe this definition is justified. Furthermore, these data come from a large, prospectively evaluated cohort of patients treated with a homogeneous protocol including daily IG and positional correction; thus the observed difference in LS incidence is credible. 
Pak and colleagues suggest that concurrent neurotoxic chemotherapy may contribute to a higher incidence of LS [13]. The odds ratio for cisplatin on univariate analysis is 1.23 (95\% confidence interval is 0.5 to 2.3 ). Thus, we cannot conclude that there is an effect from cisplatin. It may be that our study was underpowered to detect such an effect, and there may be a confounding effect of separate factors linked with cisplatin use such as age, hypertension and diabetes.

Surprisingly, $\mathrm{V}_{20 \%}$ was significantly lower on univariate analysis in patients with LS, although its effect was insignificant in the multi-variate model. Conversely, $\mathrm{V}_{40 \text { Gy }}$ and $\mathrm{V}_{40 \%}$ were insignificant on univariate analysis but significant according to the logistic regression model, consistent with previous work [13]. Of note, TomoTherapy plans confer excellent spinal cord sparing, meaning only $27.3 \%$ of all the patients in our cohort had a partial cord volume receiving 40 Gy or more. Therefore, our $\mathrm{V}_{40 \mathrm{~Gy}}$ results should be interpreted with caution. Mean $\mathrm{D}_{\max }$ in our cohort was 36.4 Gy compared to 39.1 to 42.5 Gy in similar studies using VMAT and IMRT respectively [12, 13], yet more patients in our cohort reported LS than in these studies. Interestingly, a study on 105 patients receiving thoracic IMRT for lymphoma reported a mean $\mathrm{D}_{\max }$ of 33.5 Gy and had an LS incidence of $29 \%$ [5], also suggesting factors other than dose may be important. According to our multi-variate analysis, age, diabetes, and unilateral neck radiation may be related factors, although given the sample size and degrees of freedom in the model, $p$-values for all factors should be considered borderline significant, and interpreted with caution.

Patients developing LS were younger than patients without LS. The difference was insignificant on univariate analysis and binary logistic regression, but significant in the ordinal regression, suggesting younger patients have more severe symptoms if they do develop LS. These findings are not new: Mul and co-workers found a mean age of 52 in LS patients compared with 61 in non-LS patients [15], whilst Leung et al. found a decreased risk in those over 60 [10]. Although younger patients were more likely to receive cisplatin $(p=0.0017)$ they were not more likely to receive a higher maximum or mean SC dose ( $r=0.030$ and -0.203 respectively, Pearson correlation coefficient).

Intriguingly, our data suggest that patients with diabetes are less likely to develop LS, a previously unreported finding. It should be noted that $10.2 \%$ of our cohort had diabetes compared to $3.9 \%$ and $4.1 \%$ in similar studies $[13,15]$. Nine of 13 diabetic patients in our cohort took metformin (the one diabetic patient with LS also took metformin). This drug has been suggested to have anti-inflammatory and anti-oxidant neuroprotective effects in mouse models of MS [25, 26], whilst a significant antiinflammatory effect of metformin and pioglitazone has also been shown in patients with MS and metabolic syndrome [27]. However, more investigation would be needed to ascertain whether these benefits are also seen in radiation-induced demyelination.

Lastly, patients with LS were significantly more likely to have had unilateral neck radiation. A 'bath and shower' effect, whereby radiation tolerance is reduced if an area of high dose is surrounded by an area of low dose, was first demonstrated in rat spinal cords [16, 28]. It is hypothesised that low dose radiation prevents oligodendrocyte migration to repair damage, and can alter gene expression $[29,30]$. This effect was sought, but not found in a previous clinical study [13]. However, Ko and colleagues observed LS exclusively in patients that received unilateral radiotherapy (5 of 33 patients), and suggest that axial dose inhomogeneity may contribute to the development of LS [12]. Other authors postulate that anterior-posterior dose gradients may be significant because of spinothalamic tract damage [31].

In addition to a relationship between unilateral neck irradiation and LS, we also found that unilateral neck treatment plans had much more inhomogeneous SC dosimetry. Although this inhomogeneity was not an independent risk factor for LS in the multi-variate model, this may be due to the close association with treatment laterality, and the possibility of diluted statistical power within the model. Our interpretation of these data are as follows; firstly, to corroborate previous findings of higher LS risk in patients undergoing unilateral neck treatment, secondly to suggest that inhomogeneous SC dose distributions may be a mechanistic factor in this effect, and finally that a paradoxically rising incidence of LS may in part be due to the greater SC dose inhomogeneity that IMRT confers. It is clear however that understanding of neurological response to complex dose distributions is incomplete.

\section{Conclusion}

The incidence of LS in this study remains paradoxically higher than previously reported, despite modern IMRT techniques delivering low SC doses. We found no increased risk from concomitant cisplatin, but confirmed previously reported higher risk in younger patients, and with higher volumes of SC receiving $\geq 40$ Gy. Diabetes appeared to reduce risk, and unilateral neck treatment was associated with LS. Greater SC dose inhomogeneity may explain this finding, but further work on neurological response to complex dose distributions is required. 


\section{Additional file}

Additional File 1: Figure S1. The relevant question from the clinical reporting form Shows the question patients were asked to grade severity of LS from 1 to 4. Figure S2. Maximum spinal cord dose in patients with unilateral and bilateral neck radiation Box and whisker plot showing no difference in $D_{\max }$ for patients with unilateral and bilateral neck radiation. Figure S3. Dose parameters in patients with no LS symptoms (unshaded, $n=75$ ), and with LS (shaded, $n=42$ ) $\mathbf{A}$ - Dose to spinal cord. B - Volume of spinal cord receiving 10, 20,30, and 40 Gy. C - Percentage of spinal cord receiving 10, 20, 30, and $40 \mathrm{~Gy}$. Figure S4. Dose parameter multicollinearity plots. $\mathbf{A}-\mathrm{V}_{20 \%}$ Vs $V_{30 \%}$. $\mathbf{B}-\mathrm{V}_{20 \%}$ Vs $V_{40 \%}$ Scatter plots showing significant multicollinearity between $V_{20}$ and $V_{30 \%}$, but less collinearity between $V_{20 \%}$ and $V_{40 \%}$. Table $\mathbf{S} 1$. Collinearity statistics for models containing $V_{20 \%}, V_{30 \%}$, and $V_{40}$ Tables showing variance inflation factor and tolerance statistics for logistic regression models containing $A V_{20 \%}, V_{30 \% \text {, }}$ and $V_{40 \%}$ (high collinearity); and $B V_{20 \%}$ and $V_{40 \%}$ (low collinearity). Table S2. Ordinal logistic regression with highest reported grade of LS as the dependent variable Logistic regression output showing younger age and absence of diabetes are significantly associated with higher grade LS.

Table S3. Binary logistic regression with LS vs Non-LS as the dependent variable, and absolute dose volumes (in cc). Logistic regression output showing that using absolute volume or percentage volume makes little difference to the predictive power of the model or the odds ratio for variables in the refined model. Table S4. Ordinal logistic regression with highest reported grade of LS as the dependent variable, and absolute dose volumes (in cc). Logistic regression output showing that using absolute volume or percentage volume makes little difference to the predictive power of the model or the odds ratio for variables in the refined model. (PDF $234 \mathrm{~kb}$ )

\section{Abbreviations}

Cl: Confidence interval; CT: Computed tomography; CTCAE: Common terminology criteria for adverse events; CTV: Clinical target volume; $D_{2} \mathrm{~cm}^{3}$ : The minimum dose to the $2 \mathrm{~cm}^{3}$ of the spinal cord receiving the highest dose; $D_{\text {max }}$ : Maximum point dose to the spinal cord; EORTCQLQ: European organisation for research and treatment of cancer quality of life questionnaire; HNC: Head and neck cancer; IBM

SPSS: International business machines corporation statistical package for social sciences; IG: Image guidance; IMRT: Intensity modulated radiotherapy; KPS: Karnofsky performance status; LENTSOM(A): late effects normal tissue task force - subjective objective, management, analytic; LS: L'Hermitte's sign; MRI: Magnetic resonance imaging; MS: Multiple sclerosis; OAR: Organ at risk; OR: Odds ratio; PET: Positron emission tomography; PRV: Planning organ at risk volume; PTV: Planning target volume; ROC: Receiver operator characteristic; RT: Radiotherapy; SC: Spinal cord; SCC: Squamous cell carcinoma; SGT: Salivary gland tumour; $V_{40 \%}$ : Percentage volume of spinal cord receiving 40Gy or more; $V_{40 G y}$ : Absolute volume of spinal cord receiving 40Gy or more; VMAT: Volumetric modulated arc therapy

\section{Acknowledgements}

The authors wish to acknowledge and thank Dr. Marina Romanchikova for assistance with data preparation and transfer.

\section{Funding}

The VoxTox programme received a 5 year programme grant from Cancer Research UK (CRUK) [grant number CRUKJA13405]. DJN received funding from Addenbrooke's Charitable Trust and CRUK [grant numbers 24/15 A/Noble RG82557, and C20/A20917]. NGB was supported by the Cambridge Biomedical Research Centre. No funding sources were involved in study design or analysis.

\section{Availability of data and materials}

The datasets used and/or analysed during the current study are available from the corresponding author on reasonable request.

\section{Authors' contributions}

HML and DJN analysed and interpreted patient data and were major contributors in writing the manuscript. GCB and JRF were involved in statistical analysis and reporting. $\mathrm{AMB}$ was the study research radiographer who collected all patient data. RJB and SJJ recruited patients to the study. RJ and NGB made substantial contributions to conception and design of the study. All authors read and approved the final manuscript.

\section{Ethics approval and consent to participate}

VocTox received National Research Ethics Service (NRES) Committee East approval in February 2013 (13/EE/0008).

\section{Competing interests}

The authors declare that they have no competing interests.

\section{Publisher's Note}

Springer Nature remains neutral with regard to jurisdictional claims in published maps and institutional affiliations.

\section{Author details}

'Foundation Doctor, Northampton General Hospital, Cliftonville, Northampton NN1 5BD, UK. ${ }^{2}$ VoxTox Research Group, Cambridge University Dept. of Oncology, Hutchison/MRC Research Centre, Box 197 Cambridge Biomedical Campus, Cambridge CB2 OXZ, UK. ${ }^{3}$ Oncology Centre, Addenbrooke's Hospital, Cambridge University Hospitals NHS Foundation Trust, Hills Road, Cambridge CB2 0QQ, UK. ${ }^{4}$ Cambridge Clinical Trials Unit, Cambridge University Hospitals NHS Foundation Trust, Hills Rd, Cambridge CB2 0QQ, UK. ${ }^{5}$ Division of Cancer Sciences, University of Manchester, Manchester Cancer Research Centre, Manchester Academic Health Science Centre, and the Christie NHS Foundation Trust, Manchester, UK

Received: 29 November 2017 Accepted: 5 April 2018

Published online: 04 May 2018

\section{References}

1. Kirkpatrick JP, van der Kogel AJ, Schultheiss TE. Radiation dose-volume effects in the spinal cord. Int J Radiat Oncol Biol Phys. 2010;76:S42-9. http:// www.redjournal.org/article/S0360-3016(09)03296-9/fulltext.

2. Thomson D, Yang $H$, Baines $H$, et al. NIMRAD - a phase III trial to investigate the use of nimorazole hypoxia modification with intensity-modulated radiotherapy in head and neck cancer. Clin Oncol (R Coll Radiol). 2014;26: 344-7. http://www.clinicaloncologyonline.net/article/S0936-6555(14)000867/fulltext.

3. Miah AB, Bhide SA, Guerrero-Urbano MT, et al. Dose-escalated intensitymodulated radiotherapy is feasible and may improve locoregional control and laryngeal preservation in laryngo-hypopharyngeal cancers. Int J Radiat Oncol Biol Phys. 2012;82:539-47. http://www.redjournal.org/article/S03603016(10)03458-9/fulltext.

4. Brownlee WJ, Hardy TA, Fazekas F, et al. Diagnosis of multiple sclerosis: progress and challenges. Lancet. 2017;389:1336-46. http://www.thelancet. com/journals/lancet/article/PIIS0140-6736(16)30959-X/fulltext.

5. Youssef B, Shank J, Reddy JP, et al. Incidence and predictors of Lhermitte's sign among patients receiving mediastinal radiation for lymphoma. Radiat Oncol. 2015;10:206. https://ro-journal.biomedcentral.com/articles/10.1186/ s13014-015-0504-7.

6. Atkinson SL, Li YQ, Wong CS. Apoptosis and proliferation of oligodendrocyte progenitor cells in the irradiated rodent spinal cord. Int J Radiat Oncol Biol Phys. 2005;62:535-44. http://www.redjournal.org/article/S0360-3016(05)00235X/fulltext.

7. St Clair WH, Arnold SM, Sloan AE, et al. Spinal cord and peripheral nerve injury: current management and investigations. Semin Radiat Oncol. 2003; 13:322-32. 10.1016/S1053-4296(03)00025-0 http://www.semradonc.com/ article/S1053-4296(03)00025-0/fulltext.

8. Jones, A. Transient radiation myelopathy (with reference to LHERMITTE'S sign of electrical PARAESTHESIA). Br J Radiol 1964; 37: 727-744. http://www. birpublications.org/doi/abs/.

9. Esik $O$, Csere $T$, Stefanits $K$, et al. A review on radiogenic Lhermitte's sign. Pathol Oncol Res. 2003;9:115-20. PAOR.2003.9.2.0115 http://por. hu/2003/9/2/0115/0115a.pdf

10. Leung WM, Tsang NM, Chang FT, et al. Lhermitte's sign among nasopharyngeal cancer patients after radiotherapy. Head Neck. 2005;27:187-94. http:// onlinelibrary.wiley.com/doi/10.1002/hed.20140/abstract.

11. Fein DA, Marcus RB Jr, Parsons JT, et al. Lhermitte's sign: incidence and treatment variables influencing risk after irradiation of the cervical spinal cord. Int J Radiat Oncol Biol Phys. 1993;27:1029-33. http://www.redjournal.org/article/03603016939 05192/abstract.

12. Ko HC, Powers AR, Sheu RD, et al. Lhermitte's sign following VMAT-based head and neck radiation-insights into mechanism. PLoS One. 2015:10: e0139448. https://www.ncbi.nlm.nih.gov/pmc/articles/pmid/26448647/. 
13. Pak $D$, Vineberg $K$, Feng $F$, et al. Lhermitte sign after chemo-IMRT of headand-neck Cancer: incidence, doses, and potential mechanisms. Int J Radiat Oncol Biol Phys. 2012;83:1528-33. http://www.ncbi.nlm.nih.gov/pmc/ articles/PMC3481166/.

14. Schultheiss TE. The radiation dose-response of the human spinal cord. Int J Radiat Oncol Biol Phys. 2008;71:1455-9.

15. Mul VEM, de Jong JMA, Murrer LHP, et al. Lhermitte sign and myelopathy after irradiation of the cervical spinal cord in radiotherapy treatment of head and neck cancer. Strahlenther Onkol. 2011;188:71-6. http://link. springer.com/article/10.1007/s00066-011-0010-2.

16. Bijl HP, van Luijk P, Coppes RP, Schippers JM, Konings AWT, van der Kogel AJ, Unexpected changes of rat cervical spinal cord tolerance caused by inhomogeneous dose distributions. International Journal of Radiation Oncology*Biology*Physics. 2003;57(1):274-281.

17. Burnet NG, Scaife JE, Romanchikova M, Thomas SJ, Bates AM, Wong E, Noble DJ, Shelley LEA, Bond SJ, Forman JR, Hoole ACF, Barnett GC, Brochu FM, Simmons MPD, Jena R, Harrison K, Yeap PL, Drew A, Silvester E, Elwood P, Pullen H, Sultana A, Seah SYK, Wilson MZ, Russell SG, Benson RJ, Rimmer YL, Jefferies SJ, Taku N, Gurnell M, Powlson AS, Schönlieb C-B, Cai X, Sutcliffe MPF, Parker MA. Applying physical science techniques and CERN technology to an unsolved problem in radiation treatment for cancer: the multidisciplinary 'VoxTox' research programme. CERN IdeaSquare Journal of Experimental Innovation. 2017;1 (1):3. https://doi.org/10.23726/cij.2017.457.

18. Burnet NG, Adams EJ, Fairfoul J, Tudor GSJ, Hoole ACF, Routsis DS, Dean JC, Kirby RD, Cowen M, Russell SG, Rimmer YL, Thomas SJ. Practical Aspects of Implementation of Helical Tomotherapy for Intensity-modulated and Imageguided Radiotherapy. Clinical Oncology. 2010;22(4):294-312.

19. Bonner JA, Harari PM, Giralt J, Cohen RB, Jones CU, Sur RK, Raben D, Baselga J, Spencer SA, Zhu J, Youssoufian H, Rowinsky EK, Ang KK. Radiotherapy plus cetuximab for locoregionally advanced head and neck cancer: 5-year survival data from a phase 3 randomised trial, and relation between cetuximabinduced rash and survival. The Lancet Oncology. 2010;11(1):21-28

20. U.S. Department of Health and Human Services. CTCAE 4.03: National Cancer Institute; 2010. https://evs.nci.nih.gov/ftp1/CTCAE/CTCAE_4.03/ CTCAE 4.03 2010-06-14_QuickReference 8.5x11.pdf

21. Lent soma scales for all anatomic sites. International Journal of Radiation Oncology*Biology*Physics. 1995;31(5):1049-1091.

22. ICRU. International commission on radiation units and measurements. Report 83: prescribing, recording, and reporting photon-beam intensitymodulated radiation therapy (IMRT). J ICRU. 2010;10:27-40.

23. Bonett DG, Price RM. Statistical inference for a linear function of medians: Confidence intervals, hypothesis testing, and sample size requirements.. Psychological Methods 2002;7(3):370-383.

24. Derksen S, Keselman HJ. Backward, forward and stepwise automated subset selection algorithms: Frequency of obtaining authentic and noise variables. British Journal of Mathematical and Statistical Psychology. 1992;45(2):265-282.

25. Nath N, Khan M, Paintlia MK, Hoda MN, Giri S. Metformin Attenuated the Autoimmune Disease of the Central Nervous System in Animal Models of Multiple Sclerosis. The Journal of Immunology. 2009;182(12):8005-8014.

26. Paintlia AS, Paintlia MK, Mohan S, Singh AK, Singh I. AMP-Activated Protein Kinase Signaling Protects Oligodendrocytes that Restore Central Nervous System Functions in an Experimental Autoimmune Encephalomyelitis Model. The American Journal of Pathology. 2013;183(2):526-541.

27. Negrotto L, Farez MF, Correale J. Immunologic Effects of Metformin and Pioglitazone Treatment on Metabolic Syndrome and Multiple Sclerosis. JAMA Neurology. 2016;73(5):520.

28. Bijl HP, van Luijk P, Coppes RP, Schippers JM, Konings AWT, van der Kogel AJ. Influence of adjacent low-dose fields on tolerance to high doses of protons in rat cervical spinal cord. International Journal of Radiation Oncology*Biology*Physics. 2006;64(4):1204-1210.

29. Chari DM, Huang WL, Blakemore WF. Dysfunctional oligodendrocyte progenitor cell (OPC) populations may inhibit repopulation of OPC depleted tissue. Journal of Neuroscience Research. 2003;73(6):787-793.

30. Nieder C, Andratschke N, Astner AT. Experimental concepts for toxicity prevention and tissue restoration after central nervous system irradiation. Radiat Oncol. 2007;2:23. https://doi.org/10.1186/1748-717X-2-23.

31. Dong C. Lim, Patrick J. Gagnon, Sophia Meranvil, Darryl Kaurin, Linda Lipp, John M. Holland. Lhermitte's Sign Developing after IMRT for Head and Neck Cancer. International Journal of Otolaryngology. 2010;2010:1-4.

\section{Ready to submit your research? Choose BMC and benefit from:}

- fast, convenient online submission

- thorough peer review by experienced researchers in your field

- rapid publication on acceptance

- support for research data, including large and complex data types

- gold Open Access which fosters wider collaboration and increased citations

- maximum visibility for your research: over $100 \mathrm{M}$ website views per year

At BMC, research is always in progress.

Learn more biomedcentral.com/submissions 